\section{SOLETR AS \\ R \\ S T}

\title{
Aproximações cambiantes
}

Consideram-se, portanto, as aventuras e as metamorfoses do signo, que, para além de sua versatilidade, dado que pertence, ao mesmo tempo e de maneira entrecruzada, a vários sistemas semióticos, instaura, concomitantemente, uma afirmação e uma negação, uma presença e uma ausência, um verso e reverso, travando uma luta entre o significante e o significado: palavras no espelho da linguagem, ecos no deserto dos sistemas de signos.

Latuf Isaias Mucci (2009) ${ }^{1}$

Quando o saudoso colega Latuf Isaias Mucci participou de uma Banca para professor adjunto na Faculdade de Formação de Professores da UERJ, em 2010, tornou a semana do concurso um encontro amigável entre pares e ímpares. Com uma energia invejável, chegava a São Gonçalo às 06h30min da manhã - antes de todos nós - e passeava pelo campus até a hora de a cantina abrir. Tomava uma xícara de café e às $07 \mathrm{~h} 30 \mathrm{~min}$ nos recebia com sorriso nos olhos. E o ponto alto daqueles dias foi quando Latuf, olhando de frente para a Faculdade, abriu os braços e falou, encantado, que o nosso prédio, no bairro Paraíso, era uma verdadeira Acrópole...

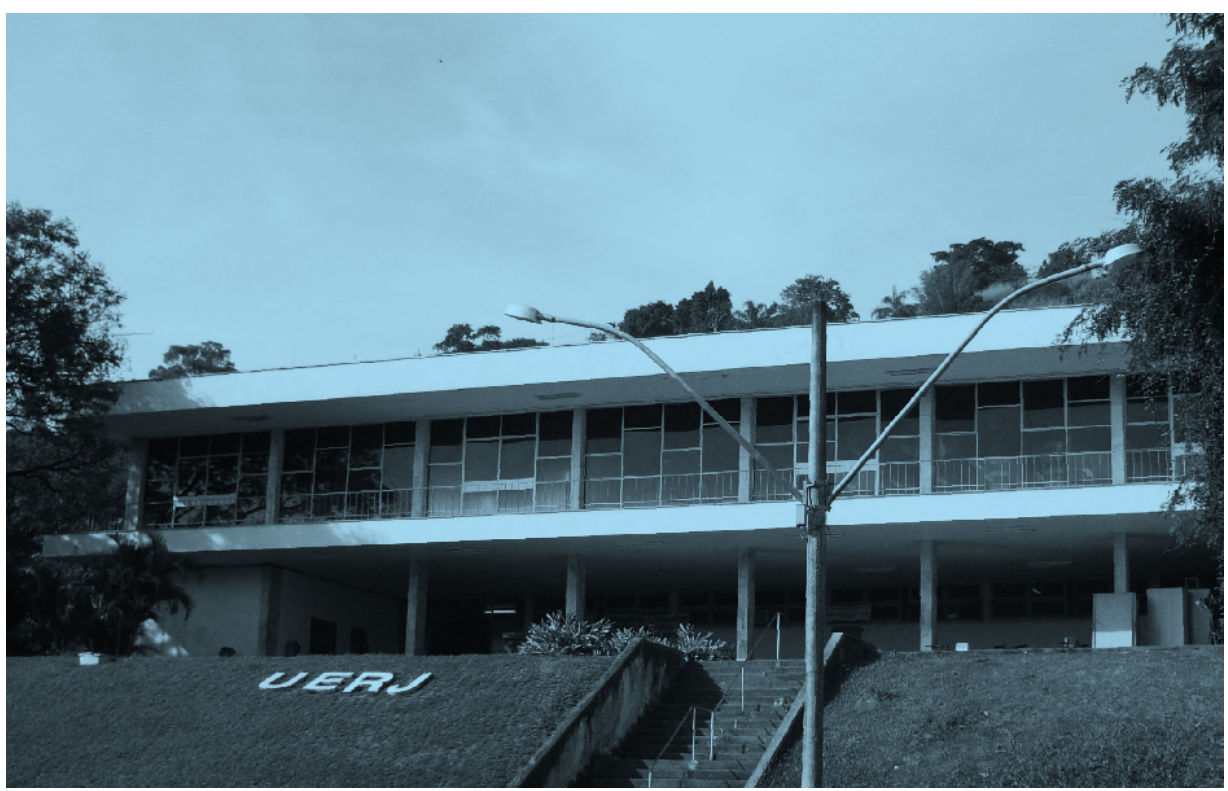

\footnotetext{
${ }^{1}$ MUCCI, Latuf Isaias. Curso: Da Semiologia à Semiótica. 2009. Niterói, RJ, Universidade Federal Fluminense (UFF) Instituto de Arte e Comunicação Social. Programa de Pós-Graduação em Ciência da Arte (PPGCA). Disponível em http://www.uff.br/cienciadaarte/arquivos/latuf_1-2009.pdf. Acesso em 02 de fevereiro de 2012.
} 
Sem estabelecer hierarquias na sua simbólica alusão, logo entendemos que Latuf comprazia-se na fruição estética das imagens, sem congelar o aspecto demasiado humano de seu olhar. Crítico atento, destilava observações hilárias, agulhadas de acupuntura nem sempre previstas pelo consenso.

Apaixonado pela literatura finissecular, pelo decadentismo, amante de Salomé, com seus múltiplos véus e representações, estudou poetas diversos. Defensor ferrenho de Oscar Wilde - autor que, segundo o próprio Latuf, está no fundamento da estética do simulacro como a verdade da arte; leitor de D’Annunzio e Pessoa - “dramatis personae - (...) tão verdadeiras suas máscaras que estas se colaram de tal modo ao rosto etéreo do Poeta que com o próprio rosto se fundiram e se confundiram"2 -, o professor respirava intersemiose, intertextualidade, redes simbólicas, migrações, deslocamentos, oferecendo, na bandeja acadêmica, não a cabeça desconectada de São João Batista, mas partes do seu eu reunidas e amalgamadas por uma forte alegria de ler e escre(vi)ver. E nada mais justo do que lhe dedicar esse número da SOLETRAS, cujo dossiê trata de Leituras Intersemióticas.

Pelo aprendizado e pela rara convivência, a nossa gratidão. Embora não esteja mais aqui, para brindar conosco a homenagem, queremos deixar registrada a nossa admiração a você, caríssimo colega e companheiro de jornada.

Ora, sabemos que o mundo contemporâneo é, sobretudo, visual. As múltiplas mídias e manifestações culturais são técnicas e procedimentos voltados à circulação e compartilhamento de saberes, enfim, à expressão, comunicação e transmissão de imagens - o que inclui, muitas vezes, para alguns, a percepção do próprio texto escrito como recurso imagético. Outros, como Roland Barthes, reconhecem o lugar do texto literário como carrochefe e, enquanto semiólogo, propunha articular "saberes em torno do desejo do saber-sabor, sem dicotomia de fronteiras, antes como inter-relação sígnica” (BARTHES apud LATUF,

\footnotetext{
2 MUCCI, Isaías Latuf. Nascemos todos e vivemos sob o signo do simulacro. Disponível em: http://www.blocosonline.com.br/literatura/prosa/artigos/art064.php.
} 


\section{SOLETR AS}

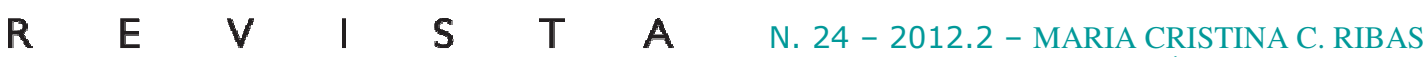
PAULO CÉSAR S. OLIVEIRA

2010, p. 2) ${ }^{3}$. Na perspectiva barthesiana, a interdisciplinaridade consistiria em criar um objeto novo que não pertencesse a ninguém - a literatura.

Acrescenta-se ao (nosso) sonho interdisciplinar ${ }^{4}$ (JAPIASSU, 2006) o dado de que orientações recentes da Literatura Comparada ${ }^{5}$ têm conferido força aos diálogos Literatura e outras Artes, outras ciências e disciplinas, além de sinalizar a relevância e a demanda contemporânea de "pôr em relação", ler as diferenças e as contribuições mútuas. Sem o peso da dívida - de quem é tomado como modelo e fica superior ao outro e, por isso, nunca tem como chegar a seus pés -, as relações se desdobram 'em rede', no duplo sentido que a expressão aqui permite. O jogo intertextual e a metodologia interdisciplinar facultam o trânsito entre as diversas linguagens. Afinal, de acordo com Kristeva ${ }^{6}$, "todo texto se constrói como mosaico de citações, é absorção e trans-formação de outro texto".

O dossiê da revista SOLETRAS n. 24 traz ao proscênio esse debate - intertextual e interdisciplinar - seja através de discussões de ordem conceitual, seja através de leituras na interface das linguagens e nas modalidades artísticas diversas. Enfim, procedimentos que acionam e/ou são acionados por sistemas intersemióticos - muitas vezes alavancados pela indústria cultural, com a finalidade de explicitar procedimentos que demandam outro perfil de leitor, um olhar atento e aberto para novas posturas no mundo contemporâneo.

$\mathrm{O}$ artigo "Escritas do olhar: algumas relações possíveis entre palavra e imagem no contexto da construção estética da modernidade", de Marcus Sampaio Salgado, analisa a articulação palavra-imagem no contexto da modernidade. A conjunção poesia e visualidade tem passado, segundo o autor, por várias tentativas de sistematização que "remetem à cena da origem da própria linguagem escrita”. Neste sentido, lembra que os compêndios de histórias da arte e da literatura estão lotados de procedimentos e descrições que apontam para a "textualização do espaço figural" e da "figuração do espaço textual”, assim como os híbridos icônico-verbais nos domínios da indústria cultural. A equivalência poesia pintura - ut pictura poesis - inclui Plutarco, Aristóteles, Horácio, Da Vinci na discussão que se desenvolve ao longo dos séculos e que antecipa a semiótica contemporânea. Para o autor, "a libertação do material artístico é nuclear nas poéticas da visualidade”, o que se desdobra na lógica dos jogos de linguagem e em suas relações com a criatividade.

\footnotetext{
${ }^{3}$ Disponível: http://www.ufjf.br/darandina/files/2010/12/Da-interdisciplinaridade-segundo-o-c\%C3\%B3digo-deRoland-de-Barthes.pdf Acesso a 02-02-13.

${ }^{4}$ JAPIASSU, Hilton. $O$ sonho transdisciplinar e as razões da filosofia. Rio de Janeiro: Imago, 2006.

${ }^{5}$ CARVALHAL, Tania. Literatura comparada. São Paulo: Ática, 2006.

${ }^{6}$ KRISTEVA, Julia. Introdução a semanálise. São Paulo: Perspectiva, 1974, p. 64 (Debates semiótica).
} 


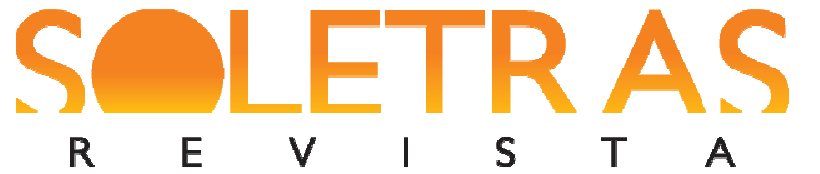

R
N. 24 - 2012.2 - MARIA CRISTINA C. RIBAS PAULO CÉSAR S. OLIVEIRA

Mark Macleod nos brinda com um artigo circunscrito à polêmica da fidelidade de uma obra literária a sua releitura pelo cinema: refere-se ao livro de Brian Selznick, "A invenção de Hugo Cabret", que inspira o filme homônimo de Martin Scorcese. Macleod discute a interferência do meio na construção da subjetividade e o temor do artista em relação à dependência de seu trabalho em relação ao de outro. Nesta perspectiva, a preocupação do livro com o roubo aponta para a reflexão lacaniana sobre a origem da subjetividade e da culpa. Por definição, a adaptação é dependente de outro texto e representa, simultaneamente à continuidade, um constante reposicionamento do "adaptador", o que inclui, dentre outros procedimentos, um previsto deslocamento das ênfases originais da história no processo de releitura. Nas palavras de Macleod, "Scorsese's film finally rejects the concept of the artist as either thief or orphan".

O artigo de Lucia Helena, "Novo nome para um velho Império: ética e literatura no mercado da globalização", borda, com maestria, uma rede (des) fiável de questões prementes na contemporaneidade. Nas palavras da autora, as quatro narrativas que elege, em sua análise, "expõem algumas das chagas a doer na carne da escrita contemporânea e a descerrar, quem sabe, os véus do olhar do leitor-consumidor." Ao aliar exemplarmente ética, paradoxo, autoria e a heteronímia na relação entre literatura, memória e mercado, em A via crucis do corpo, de Clarice Lispector; Verão, de J. M. Coetzee; Budapeste, de Chico Buarque de Holanda; e Diário de um ano ruim, de J. M. Coetzee, Lucia Helena nos brinda com um trabalho seguro, escrita fluida e incisiva sobre questões que são produzidas dentro - e fora - do âmbito literário, na interface linguagem e mercado, e mesmo assim incidem diretamente sobre ele. Relatando que tal "caso" com os ditames do consumo já é percebido em Fedro, de Platão, e em outros exemplos de tirar o fôlego, Lucia arremata: "Para não tornar irresponsável esta viagem, dos gregos ao contemporâneo, coloco ao público a pergunta que trago na ponta da língua: o que significa, no século XXI, a relação entre o mercado e a literatura e vice-versa?"

Em diálogo com a questão apontada por Lucia Helena, que incide sobre a autonomia do autor no processo de composição da obra, e mais voltado para o âmbito do cinema, o artigo de Miguel Pereira oferece-nos outra interface: desta vez, a questão da concepção de autoria coletiva. O olhar sensível do autor traz, ao cenário da discussão, o filme Tickets (2005), de Ermanno Olmi, Abbas Kiarostami e Ken Loach, somando ao debate a contribuição de Budapeste (2009), de Walter Carvalho, inspirado no livro homônimo de Chico Buarque (2003). No caso de Tickets, explica-nos o autor, cada história foi roteirizada por equipes 


\section{SOLETR AS}

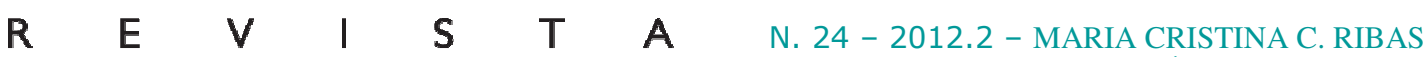
PAULO CÉSAR S. OLIVEIRA

diferentes e as harmonizações exigiam a presença de intérpretes em três línguas (italiano, iraniano e inglês). Entretanto, neste omnibus film, o que há "é um trabalho de unidade e presença em que sobressai o conjunto e não as individualidades". Complementando o debate, Miguel Pereira lembra-nos que Budapeste, ao mesmo tempo em que dramatiza as questões de autoria no próprio discurso fílmico e literário, põe em xeque narrativas experimentais.

Narrativas experimentais são trazidas ao proscênio pelo olhar atento e sensível de Marília Rothier, com sua ênfase nas imagens visuais que pontuam as experimentações literárias de Mário Peixoto, o cineasta de Limite, a poesia de Jorge de Lima e o múltiplo acervo de Lúcio Cardoso. Na interface em que habilmente transita, a autora reivindica um lugar para as produções que passam próximo ou ao largo do cânone modernista, "abrigadas em rótulo vago como o de pré-modernismo". Nessa perspectiva, ressalta que, das novas tecnologias, o cinema foi a menina dos olhos dos interessados em construir uma prosa experimental - nas palavras de Rothier, conjunto de estratégias escriturais capazes de produzir efeitos plásticos, em que "a articulação de imagens substitui a sintaxe verbal, sem, no entanto, abandonar totalmente as palavras".

$\mathrm{O}$ artigo de Gustavo Bernardo propõe uma releitura de dois filmes e uma peça de Woody Allen - escrita e dirigida por ele - respectivamente, A Rosa Púrpura do Cairo, Poderosa Afrodite e God. Mesclando tempos, interesses e procedimentos, Gustavo Bernardo propõe singular leitura que traz ao proscênio o diálogo entre Teologia e Teoria da Literatura, tendo como eixo a referência de Aristóteles sobre o Deus Ex-Machina.

Seguindo a trilha da dramaturgia, Paula Ludwig nos traz "Leituras intersemióticas sobre dramaturgia: uma perspectiva a partir do melodrama". No artigo, a autora estuda a tessitura do drama, promovendo a interface literatura e teatro e considerando a constituição de sentidos como resultado, não somente de construções lógicas, mas de "possibilidades que o sensível nos apresenta".

Assim como Paula Ludwig privilegia o aspecto sensível do humano em relação ao melodrama, o artigo de Robson Rodrigues de Paula o faz em relação à pintura: "Diálogos intersemióticos: interacionismo e pintura impressionista em cena", diz respeito a uma curiosa aproximação arte/sociedade, que passa por "Chicago, lócus de estudo dos sociólogos interacionistas, e chega a Paris, cidade protagonista do impressionismo na pintura”. O autor pressupõe a existência de pontos de contato entre os espaços urbanos citados e as produções 


\section{SOLETR AS}

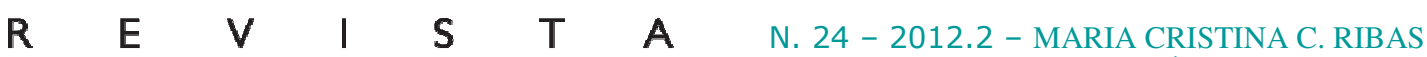
PAULO CÉSAR S. OLIVEIRA

artísticas ali produzidas, porquanto representam expressões demasiado humanas manifestas no modus operandi dos artistas criadores em foco e dos receptores dessas obras.

Partindo do pressuposto do implemento das relações interartes da produção artística na contemporaneidade, Marcela Verônica da Silva, Mariana Matheus Pereira da Silva e Moisés Gonçalves dos Santos Junior colocam em cena Anita Malfatti e Cecília Meireles, propondo “discutir a interferência dos movimentos vanguardistas do início do século XX no processo de composição artística brasileira". As obras escolhidas para o diálogo são, respectivamente, a tela "A Mulher de Cabelos Verdes" e o poema "Desenho do Sonho".

Como suplemento das nossas reflexões na área de Letras, nos chega uma pesquisa qualitativa na linha construtivista, na interface com outro campo de conhecimento: Administração. Ana Luiza S. V. Lopes e Christina Lyra C. de Souza descrevem, no âmbito das indústrias criativas, "atividades que abrangem toda a produção cultural ou artística". Nesta perspectiva, as autoras voltar-se-ão ao estudo do perfil de alguns escritores brasileiros de produção literária não canônica, identificados como artistas ou trabalhadores culturais, "procurando saber como trabalham, o que desejam, como interagem e que dificuldades enfrentam". Ressaltam que este é tipo especial de trabalho criativo, por conjugar, em suas práticas, comunicação de sentido, identificação e prazer.

Abrindo nossa seção de temas livres - a de Estudos Literários -, a Literatura Portuguesa entra em cena, com outros perfis de escritores. O artigo de Silvio César dos Santos Alves, "Arautos da modernidade: Cesário Verde, Antero de Quental, Eça de Queirós e a crise intelectual finissecular em Portugal" dramatiza a crise intelectual de fins do século XIX, a qual, conforme explica o autor, prepara o terreno para a efervescência de "procedimentos estéticos que anunciam novos valores identificados à modernidade portuguesa". Alves investiga romancistas e poetas que, assim como Baudelaire, operaram a 'desromantização do romantismo'. Silvio articula os escritores em foco, em uma tessitura exemplarmente constituída, cujo tramado denota a consistência do seu mergulho nas condições de produção daqueles que identifica como "arautos da modernidade".

Madalena Vaz Pinto apresenta Lisboa d'outra hora, agora, título inspirado em verso de Pessoa e que prenuncia um artigo claro e preciso, em que a autora propõe uma leitura da crônica "Cidade inventada", de José Cardoso Pires, nos ares da crítica pós-colonialista. Ao tecer relações entre uma escrita de mão dupla que se pretende interrogativa e ao mesmo tempo, que, como ela mesma diz, "busca intervir nos discursos ideológicos da modernidade", 


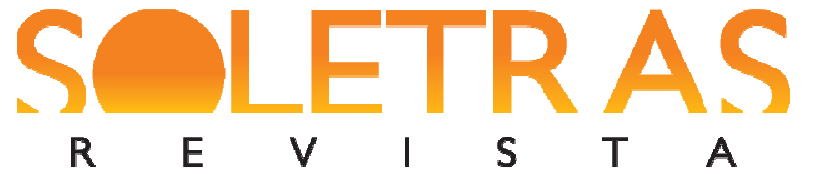

R
$\mathrm{S} \quad \mathrm{T}$

a autora identifica a pós-modernidade com a derrota do projeto moderno; projeto este fundado em metanarrativas que focavam a totalidade da experiência humana e substituído pela multiplicidade de relatos fragmentados, contingentes, que desconstroem paradigmas dicotômicos. Para fundamentar parte de sua reflexão, a autora aposta em Homi Bhabha, quando ele propõe a desconstrução dos essencialismos da linguagem evidentes no discurso ocidental, trazendo à cena contemporânea o local de enunciação da diferença.

De cartografia própria, esta seção de Estudos Literários viaja por outros lugares. Maria da Luz e Rauer Rodrigues fazem um minucioso "Retrato Introdutório de O Retrato Oval", de Edgar Allan Poe. Passo a passo bem ao gosto do poeta e contista de "A Filosofia da Composição", o estudo "microscópico" encaminhado pela dupla, que conhece de fato as traduções correntes do conto, propõe uma tradução voltada a resolver os obstáculos encontrados na passagem para outra língua, de modo a manter vivo o texto original e, ao mesmo tempo, a sua possibilidade de "transformar-se no momento em que for recontado".

De novo Poe, o artigo de Leonardo Vieira, cuja escrita poética mescla-se habilmente aos moldes acadêmicos, aponta, na leitura de The imp of the perverse, para uma sensibilidade singular que redimensiona a perversidade de um personagem o qual, inspirado em narrativas de memórias francesas, relata como teria cometido o assassinato deliberado de um leitor. Voltado a muitos detalhes, o autor do artigo desenha o cruzamento de telas de Rembrandt com o discurso cartesiano e o jogo dos radicais de palavras tão ao gosto de Poe. Com foco na análise do texto literário, Leonardo Vieira tece e entretece o enlaçamento dos discursos literário, filosófico e pictórico de modo a iluminar os jogos de linguagem e a reversão dos sentidos.

Voltando ao Brasil, o "Folhetim" e o pouco estudado "Romance-revista", no Rio de Janeiro de finais do século XIX e começo do XX, é o tema do original trabalho de Leonardo Mendes e Nathalia Gorni. Gênero satírico em prosa, sequência de cenas descosidas, o Romance-Revista valia-se de ilustrações que acompanhavam os textos para dar, ao público, ideia da suntuosidade dos palcos. Inspirado nos melodramas parisienses dos oitocentos, propunha uma crítica do passado imediato - o ano anterior -, sobretudo os eventos de maior impacto para a público leitor, sempre voltados à comicidade. O gênero, obra de autoria coletiva, é definido, pelos autores, como uma "crônica política romanceada e teatralizada sobre o ano findo", o que ratifica a contribuição desta produção não canônica para a formação 


\section{SOLETR AS}

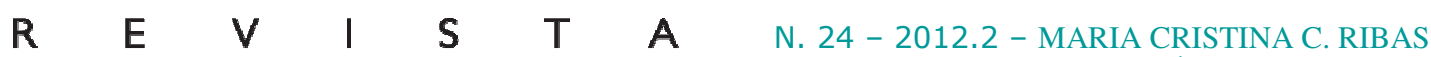
PAULO CÉSAR S. OLIVEIRA

do leitor e da literatura no Brasil. Dentre outras atitudes, o romance-revista "apostava na importância da imagem para a fruição narrativa".

Com Angela Fanini e Aline Maciel vamos ao Brasil dos modernistas. Seu trabalho " $O$ Rei da Vela, de Oswald de Andrade, e a representação simbólica do contexto industrial e tecnológico brasileiro" promove, de maneira consistente, a interação do universo simbólico constituinte do discurso literário -, com o universo material no Brasil da República Velha, enfatizando o projeto nacional de industrialização. Com ideias próprias a respeito do modernismo, as autoras apresentam as mediações formais entre literatura e contexto brasileiro da época, por meio da sátira e carnavalização da indústria nacional.

$\mathrm{O}$ artigo de Ana Cristina Coutinho Viegas nos apresenta sua pesquisa em torno da 'ucraniana brasileira' Clarice Lispector, escritora pressionada por questões financeiras que, em busca de soluções, opta pelo espaço do jornal - uma reviravolta para alguém cuja produção era identificada como "metafísica" e "hermética". Dentre outros, Clarice dedica-se à produção de crônicas, das quais Viegas analisa as publicadas entre 1967 e 1973, no Jornal do Brasil, e recolhidas no livro póstumo A descoberta do mundo. Segundo Viegas, o gênero, na interface literatura e jornalismo, configura "espaço de grande relevância para encenar subjetividades e propor reflexões metalinguísticas", além de constituir consistente exercício de (auto) crítica.

$\mathrm{Na}$ chave interdisciplinar, o trabalho de Manoel Santana reabre diálogos com a literatura, em especial parte da crônica e da poesia de Carlos Drummond, a partir da sua condição de leitor e geógrafo. Enquanto geógrafo-educador, "a experiência de ler e interessarse pelo texto drummondiano" significa "desenvolver um projeto que resgata a memória, incentiva a leitura e promove a descoberta da crônica e da poesia" do poeta de Itabira, com ênfase na "experiência humana sobre o cotidiano, memória, vida urbana e rural, história, memória e cultura".

A próxima seção livre, de Estudos Linguísticos, convida os nossos caríssimos leitores a um consistente exercício de (auto) crítica que vai compondo uma homenagem ao autor da obra analisada. Trata-se do trabalho de André Conforte, que traz à cena um livro que fez parte dos estudos de muitos de nós. De maneira clara, lógica e precisa - argumentação pedagógica -, a precisão e objetividade de Conforte faz retornar aos nossos olhos muitas das considerações, análises e exemplificações com que o autor de Comunicação em Prosa Moderna nos brindou nas aulas de produção textual, leitura e análise do texto acadêmico, 
persuasão, modos do discurso. Justa homenagem ao Mestre Othon Garcia, Conforte demonstra como o livro, cuja primeira edição é de 1967, continua atual, aliando pioneirismo à perpetuidade em termos da teoria - e prática - da argumentação.

Victoria Wilson e Amanda Almeida desenvolvem análise e argumentação pontuais da entrevista de Monica Bérgamo a Paula Toller, na Folha de São Paulo, à luz da Sociolinguística Interacional, com vistas a resolver questões no âmbito social e da pragmática relativas ao gênero em foco. Segundo as autoras, a "entrevista jornalística de alguma forma ritualizada sofre uma variação e, nessa complexa estrutura de participação que se estabelece entre os interactantes, se faz necessário identificar as condições de felicidade do gênero".

Se Victoria e Amanda trouxeram uma entrevista para análise, o próximo artigo descreve outra experiência submetida a procedimentos de análise discursiva. Em tom claro e preciso, o artigo seguinte, de Bruno Deusdará, tem apoio teórico-metodológico em Bakhtin e Maingueneau e busca "discutir possíveis contribuições de uma perspectiva discursiva para a análise de práticas intersemióticas". Seu material de análise é um vídeo produzido no período de greve das federais no ano de 2012 e enfatiza propostas de articulação dos signos verbais e não verbais.

Finalmente, para abrir a seção de Ensino, encontramos Oswaldo Mendes-Ramírez. O autor compartilha conosco um estudo detalhado para a implementação do rendimento escolar, com ênfase no ensino do espanhol na educação fundamental. Com o apoio da National Research Foundation of Korea (NRF), uma das principais contribuições da pesquisa é demonstrar as variáveis que interferem no ensino-aprendizagem; dentre elas, os efeitos do capital familiar para o rendimento escolar do aluno do sexto ano da educação primária, no contexto urbano marginal da zona metropolitana de Monterrey, no México. Durante a pesquisa, a análise da mostra - 252 famílias da região que vivem em contextos de pobreza demonstrou, dentre outros efeitos, que tais condições familiares incidem diretamente sobre o baixo rendimento escolar dos filhos. A partir dessa constatação, é possível encontrar e propor soluções para se resolver o problema educacional.

Em se tratando de questões de ensino em Portugal, trazemos o artigo "Nas entrelinhas da narrativa - entrevistas de cunho biográfico", de autoria de Fátima Pereira, Thiago Freires e Carolina da Costa Santos, que tem por objetivo avaliar "Os efeitos da escolaridade no percurso de vida dos alunos". A pesquisa privilegia a epistemologia da escuta discente, ressaltando a relevância da voz dos alunos dentro da polifonia escolar e, junto a outras 
parcerias, trata-se de um projeto interdisciplinar da Universidade do Porto. Nas palavras dos autores, o objetivo da pesquisa, então, circunscreve-se a "construir relações de saberes com a escola e não para a escola ou em vez da escola, em uma substituição de preposições que altera de fato o protagonismo dos sujeitos em pesquisa".

De volta ao Brasil, "Consideração sobre a educação do campo" é o artigo de Maria da Conceição Calmon Arruda e Lia Maria Teixeira de Oliveira, voltado aos sentidos que a Educação do Campo assume para um grupo de alunos matriculados no curso de Licenciatura em Educação do Campo (LEC), da Universidade Federal Rural do Rio de Janeiro (UFRRJ). A LEC, junto às políticas públicas, busca o fortalecimento das escolas públicas do campo e o acesso dos seus docentes à Universidade. As entrevistas junto aos docentes envolvidos demonstram a persistência para viabilizar um modelo pedagógico mais sensível às demandas das áreas rurais.

Em "Universitários vão à escola: relatos de sujeitos envolvidos na 'construção de pontes"”, Milena Domas transita, como o próprio título do artigo sugere, no delicado e fértil caminho 'entre' os citados lugares de ensino. $\mathrm{O}$ artigo relata experiências vividas no campo do saber escolar - Colégio Estadual Capitão Oswaldo Ornellas - e no campus da Faculdade de Formação de Professores da UERJ, ambos em São Gonçalo, ao mesmo tempo em que avalia as contribuições deste diálogo para o ensino e a formação discente.

$\mathrm{O}$ artigo de Marcia Alvarenga e Marcela Garcia descreve como os enunciados orais e escritos dos estudantes poderiam contribuir para o ensino da língua materna, especificamente na alfabetização inicial e continuada em turmas de EJA - Educação de jovens e adultos. Segundo as autoras, os resultados da pesquisa demonstraram que a preocupação das professoras com a correção linguística - cujo parâmetro é a 'norma culta' - foi mantida "como objetivo principal do ensino da língua materna". Entretanto, houve uma mudança, a partir do momento em que "os enunciados dos estudantes foram reconhecidos como textos", o que, por sua vez "favorece o encontro de várias consciências".

"A articulação de linguagens na leitura de textos na universidade" é o artigo de Glaucia Guimarães, com ênfase na literatura infantil. A pesquisa trata de livros, voltados para crianças, que articulam palavra, imagem e som. Conforme a autora, seu principal objetivo é reafirmar que, na leitura - especificamente de livros infantis com proposta intersemiótica - a relação dos sujeitos com o universo simbólico não se dá apenas pelas vias verbal, imagética 
ou sonora, mas, também, pela articulação destas linguagens nas práticas sociais, desenvolvidas dentro e fora das instituições de ensino.

Finalizada, agora, a apresentação dos artigos que compõem o número 24 da Revista SOLETRAS (2012), ressaltamos que, se a semiótica - pela abrangência e diversidade - não possui uma nomenclatura universalmente aceita, torna-se imprescindível, na sua clave leituras intersemióticas, estudar comparativamente termos, conceitos, expressões, matérias em diálogo. Neste interregno, as forças - e vozes - em jogo são correlações lógicas entre variáveis, descrevem oscilações, operam com instabilidades.

Retomamos, agora, as palavras do saudoso Latuf Isaias Mucci (2009, p. 1) sobre as leituras intersemióticas e seu elemento básico, o signo: a composição sígnica diz respeito, portanto, a aproximações cambiantes, forças em instável contato, atrito permanente: afirmação e negação, presença e ausência, verso e reverso, travam, em gerúndio, uma luta entre o significante e o significado. Que estes encontros aqui presentes sejam, com Latuf, "palavras no espelho da linguagem, ecos no deserto dos sistemas de signos". E ao mesmo tempo, interdependentes e não submissos, (des) concertos polifônicos, formas de interrogação, interação e compartilhamento.

Maria Cristina Cardoso Ribas

São Gonçalo, 03 de fevereiro de 2013. 